\title{
Actuation of Electro-Pneumatic System using MATLAB Simulink and Arduino Controller- A case of a Mechatronics systems Lab
}

\author{
P. Parikh ${ }^{1}$, R. Vasani ${ }^{2}$, S. Sheth ${ }^{3}$, J. Gohil $^{4}$ \\ ${ }^{1}$ Assiatant Professor, ${ }^{2}$ Director, SAL College of Engineering, Ahmedabad, Gujarat, India \\ ${ }^{3}$ Associate Professor, ${ }^{4}$ PG Student, G.H. Patel College of Engg. \& Tech., Vallabh Vidhyanagar, Aanand, India \\ \{priyam.parikh@sal.edu.in\}
}

\begin{abstract}
Mechatronics is an immerging branch in the present era which deals with mechanical systems, instrumentations and electronic systems. Hydraulic and Pneumatic systems are the vital elements of Mechatronics system. The actuation of hydraulic and pneumatic system can be done using a PLC or a microcontroller. The programming could be done in a ladder language, Functional block diagram or in embedded C. This paper shows the methodology for interfacing the MATLAB simulink with pneumatic system via microcontroller without any burden of programming. To fulfil this purpose, MATHWORKS has designed Arduino I/O packages, to communicate with Arduino controller without any programming language. The system consists of a relay unit, Arduino Microcontroller, Arduino IDE software, MATLAB simulink (Version 2012 or beyond) SMPS, Direction controlled solenoid operated valve, Double acting pneumatic cylinder and a USB cable. In a nut shell this methodology will not only decrease the load of programming but also will increase the interest of students towards Mechatronics and automation.
\end{abstract}

Keywords:Arduino controller, MATLAB Simulink, Electro-Pneumatic Mechatronics system, Serial Communication

\section{Introduction}

Nickel based alloys finds wide applications in different parts of gas turbines of aircraft, steam turbine power plants, reciprocating engines, tool \& die industry, medical field, heat treatment equipments, nuclear power plants, chemical industries, pollution control apparatus and in coal gasification and liquefaction systems. As nickel based super alloys possesses high hardness, high strength at elevated temperature, low thermal diffusivity and high chemical reactivity with the tool materials, they are very difficult to machine conventionally. This leads to nick wear of the tool nose, abrasive wear of the tool, greater diffusion wear rate, fragmentation of the tool rake face, degradation of tool material by seizure and cratering, increase in the temperature of tool tip and uneven temperature distribution in the cutting tool. [1,2]. Wire electrical discharge machining (WEDM) is one of the significant non-conventional thermoelectric process for machining of materials with high hardness, chemically reactive and which are difficult to machine using conventional methods. In WEDM material removal takes place due to melting and evaporation by thermal energy produced due to continuous discrete sparks. It finds major applications in aerospace, nuclear and automotive industries to cut intricate shapes in electrically conductive materials. Liao and Chen [3] used DEAR method for multi-objective optimization and found that the proposed method eliminates uncertainty and complication associated with PCA and Taguchi method. Sahu et.al. [4] carried out experiments on AISI D2 steel with response surface methodology to find out the effect of machining parameters on MRR, TWR, surface roughness and circularity. Data envelopment analysis was applied to find out optimal responses. Chalisgaonkar and Kumar [5] applied utility concept approach to determine optimal combination of parameters while WEDM of pure titanium. Rajyalashmi and Ramaiah [6] used grey relational analysis to carry out multi-response optimization of WEDM parameters while machining Inconel-825. Reddy et. al. [7] applied Taguchi based DEAR method to optimize the process parameters of EDM.

This paper reports multi-quality characteristic optimization of control factors while wire electrical discharge machining of Inconel-625 using Taguchi method integrated with data envelopment analysis based ranking method (DEAR). Taguchi's L27 orthogonal array was applied for experimental design. ANOVA was performed to find out the major significant factor which affects the quality characteristics.

B. Iyer, S. Nalbalwar and R. Pawade (Eds.)

ICCASP/ICMMD-2016. Advances in Intelligent Systems Research.

Vol. 137, Pp. 59-64. 


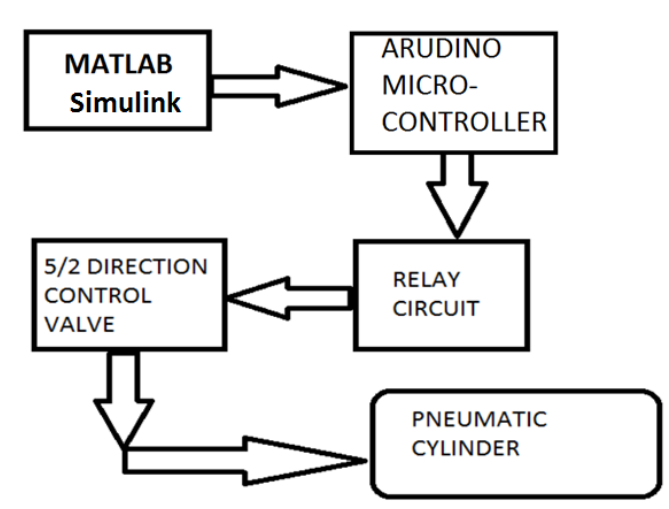

Fig. 1. Block Diagram of the system

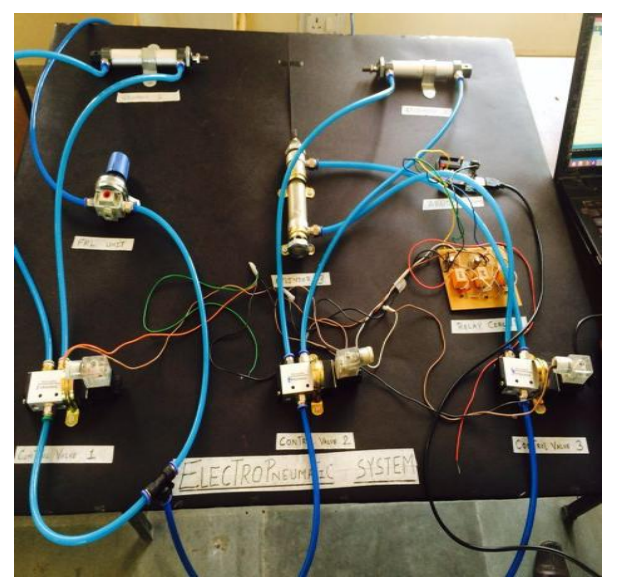

Fig. 2. Self Designed Pneumatic Trainer

\subsection{Block diagram and explanation of the system}

Fig 1 shows the block diagram of the system and figure 2 shows the actual self designed pneumatic trainer. Focusing on the block diagram, first MATLAB Simulink toolbox is connected with Arduino microcontroller using serial communication. MATHWORKS has designed Arduino I/O package to communicate with Arduino without any programming (As discussed in the introduction part) [1]. Blocks are set into the simulink to achieve a particular PSD (position step diagram) in the electro-pneumatic system. MATLAB communicated with Arduino, Arduino takes decision according to the signal feed by MATLAB and then finally triggers relays based on the logic. Relays are supposed trigger the solenoid valves, which allows passing compressed air into the pneumatic actuators [6].

Before starting the system, one needs to make sure whether MATLAB is properly connected with Arduino or not. Once it is connected successfully, a MATLAB supporting code is to be fed in Arduino's flash Memory [9]. After completion of both the tasks, a communication port is to be selected in MATLAB simulink. Communication port is a road on which data flows between Arduino and MATLAB. Arduino is connected with MATLAB using a USB cable (9600 baud rate, 8 bits) [7].

As far as the hardware is concerned, Arduino should be connected with Relay card in the TTL mode. Relay should be connected to Solenoid valves according to the logic (NO or NC). Valves should be connected to the cylinders according to the pneumatic circuit diagram [8].

\subsection{Objectives and Goals of the project}

- To get rid of Programming

- To have a alternate of PLC

- To make system user friendly

- To acquire Live Data coming from the sensors

- To design a combination of HMI and Data Acquisition

- To make system cost effective

- To reduce wiring

- To interface sensors and wireless unit without having any responsibility of coding.

- To help Mechatronics, instrumentation, mechanical and electrical students who are not much familiar with programming.

\subsection{Applications}

- Paper \& printing Industries

- Pharmaceuticals industries

- Automation and Robotics

- As a educational Trainer for students and faculties 
- Space and Radar Applications

\subsection{Project flow}

- Simulation is to be done in Automatic Studio for Electro-Pneumatic circuit

- Electronic circuit could be designed and simulate in Proteus

- Block logic could be developed in MATLAB Simulink

- Arduino controller should be properly connected with MATLAB simulink

- Relay unit should be connected with Arduino

- Solenoid Valves should be properly connected with Relay unit

- FRL unit, compressor, pressure gauge and pneumatic actuators should be connected according to the requirements

\section{Hardware and software used in the system}

Table 1 gives the information about the hardware used in the system and software details are provided in the table 2.

Table 1 Hardware used in the system

\begin{tabular}{|c|c|c|c|c|}
\hline Sr. No & Name of the Hardware & Quantity & Specifications & $\begin{array}{c}\text { Role in the } \\
\text { Project }\end{array}$ \\
\hline 1 & Arduino Controller & 1 & $\begin{array}{c}\text { 14 Digital I/O } \\
6 \text { Analog I/O } \\
32 \text { Kb Flash Memory and a } \\
\text { serial port }\end{array}$ & $\begin{array}{c}\text { Works as a } \\
\text { controller in the } \\
\text { system, which } \\
\text { accepts signals } \\
\text { from MATLAB }\end{array}$ \\
\hline 2 & Relay Unit (3 channel) & 1 & $\begin{array}{c}\text { +12 Volts, 10 Amp current } \\
\text { capacity, 1 NO and NC } \\
\text { contact }\end{array}$ & $\begin{array}{c}\text { Accepts signals } \\
\text { from Arduino and } \\
\text { passes to solenoid } \\
\text { valves }\end{array}$ \\
\hline 3 & Pneumatic Actuator & 3 & $\begin{array}{c}\text { Double Acting Actuators, 5" } \\
\text { stroke and 1" bore }\end{array}$ & $\begin{array}{c}\text { Actuates } \\
\text { according to the } \\
\text { air flow provided } \\
\text { by the valves. }\end{array}$ \\
\hline 4 & Solenoid Valve & 3 & $\begin{array}{c}5 / 2 \text { DCV, single side } \\
\text { solenoid and Spring return } \\
\text { (+12 volts and 150 mA) }\end{array}$ & $\begin{array}{c}\text { Passes } \\
\text { compressed air } \\
\text { flow toward } \\
\text { Actuators }\end{array}$ \\
\hline 5 & Compressor & 1 & $\begin{array}{c}6 \text { bar working pressure, 1 } \\
\text { phase 230 volts 10 Amp }\end{array}$ & $\begin{array}{c}\text { Compresses air } \\
\text { for the pneumatic } \\
\text { system }\end{array}$ \\
\hline
\end{tabular}

Table 2 Software used in the system

\begin{tabular}{|c|c|c|}
\hline Sr. No & Name of the Software & Specifications \\
\hline 1 & MATLAB Simulink & MATLAB 2013b is used, Arduino I/O packages are essential to download \\
\hline 2 & Arduino IDE & Arduino IDE 1.6.6 used, programming Language is embedded C \\
\hline 3 & Proteus & Electronic circuit is designed and simulated in Proteus \\
\hline 4 & Automation Studio & Electro-Pneumatic circuit is designed in Automation Studio \\
\hline
\end{tabular}




\section{Integration and simulations}

\subsection{Ariduno with MATLAB Simulink}

As discussed earlier, there are outputs in the system in the form of (Relays and valves). To achieve a position step diagram shown in the fig.3, below given block diagram is designed in the MATLAB simulink. Fig. 4 is a general method to connect Arduino and MATLAB simulink. Fig. 5 shows the block diagram generated to achieve position step diagram. Input to the system is provided in the form of square pulse. As Cylinder 1 and 2 are to be actuated simultaneously according to the PSD, common pulse is provided to both the digital pins. Cylinder 3 is provided individual pulse trainer. Here it should be noticed that, the Simulink block program may vary depends on the application. The graphical representation can be observed on the scope shown in the fig.5.

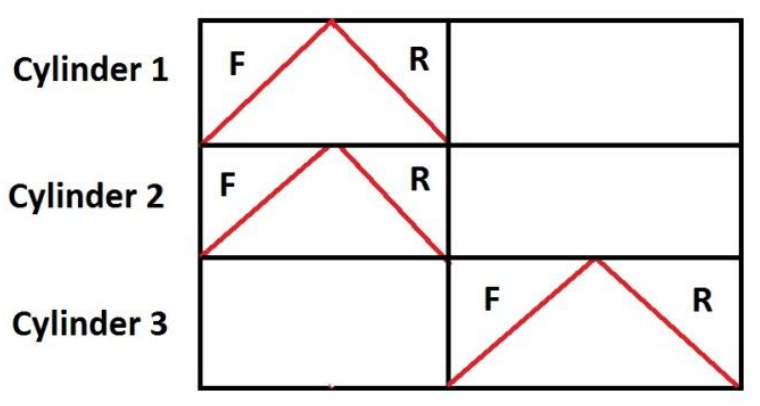

Fig. 3. Position Step Diagram

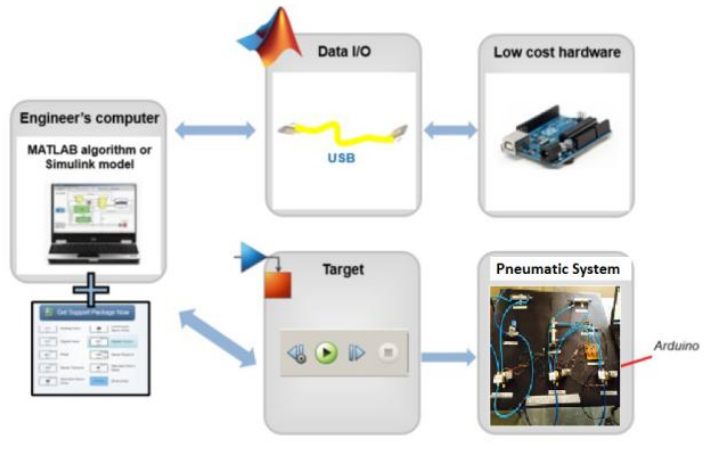

Fig. 4. Arduino and MATALB communication

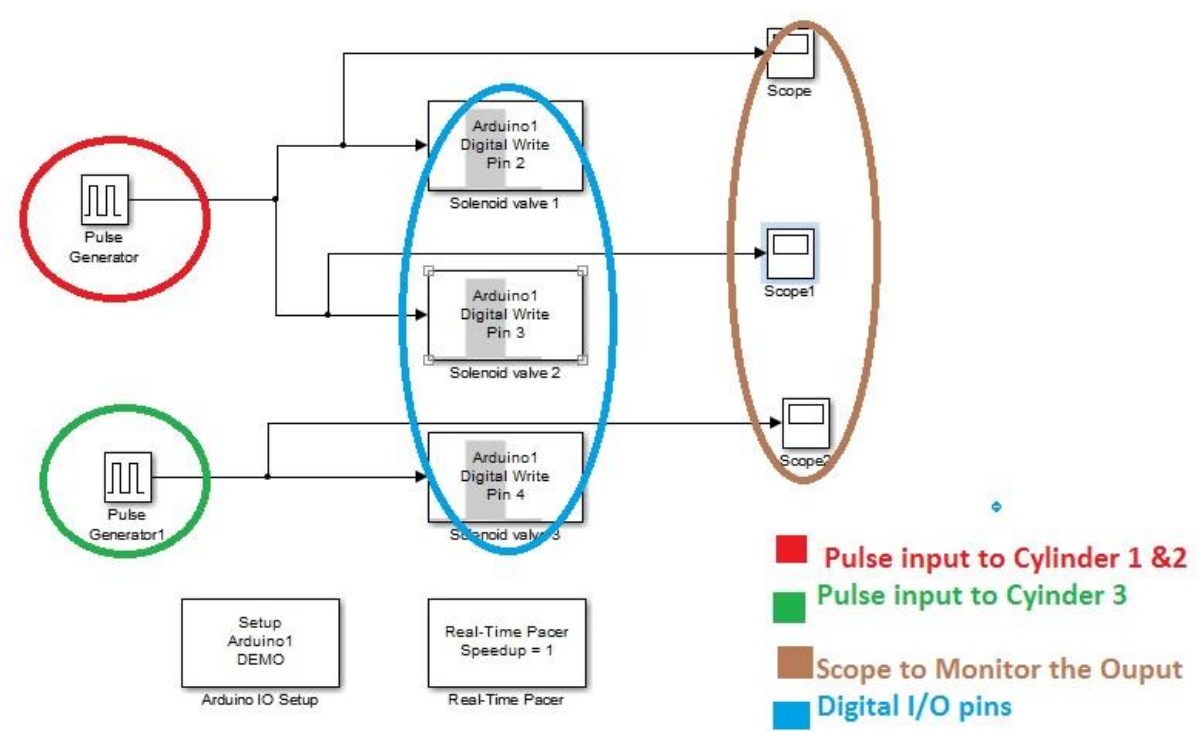

Fig. 5. MATLAB Simulink Block program

\subsection{Ariduno with MATLAB Simulink}

Figure 6 and figure 7 give are the electronic simulation and pneumatic simulation of the system respectively. As per figure 6, the Arduino controller is connected with load (valves) via electromechanical relays and ULN2003a current controller IC. These three valves can be triggered using digital pin No. 2, 3 and 4 respectively. The circuit is designed in Proteus software. Fig 7 is divided in two parts, the left one is the pneumatic circuit diagram and the right one is the electrical circuit diagram. The simulation is designed in Automation studio software. 


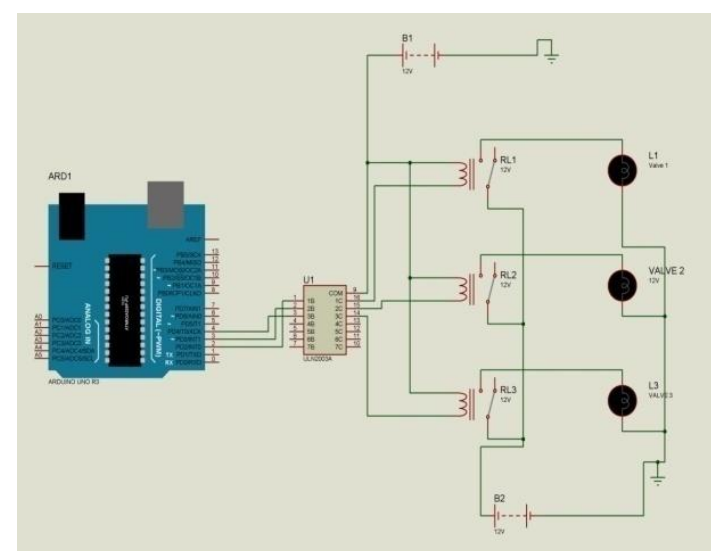

Fig. 6. Electronic circuit diagram

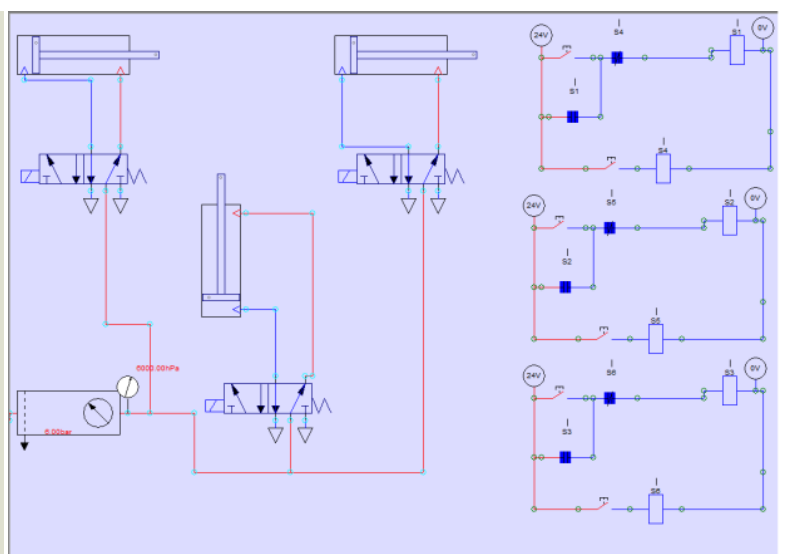

Fig. 7. Pneumatic circuit diagram

\section{Results and Discussion}

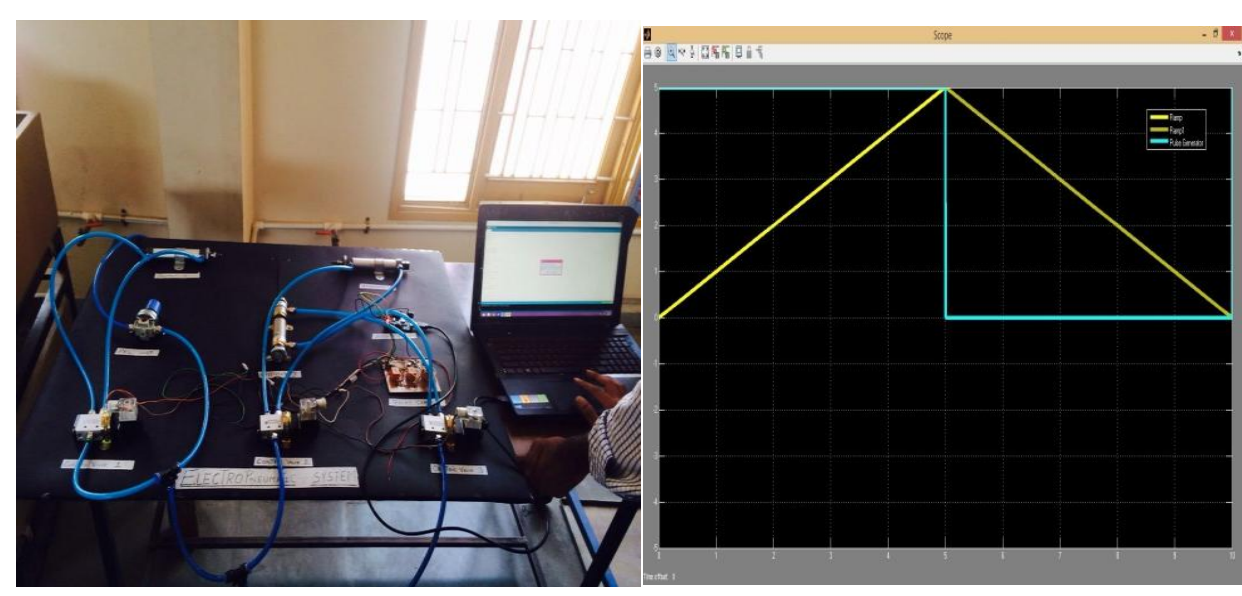

Fig. 8. Real time System

Fig. 9. Response of Cylinder 1

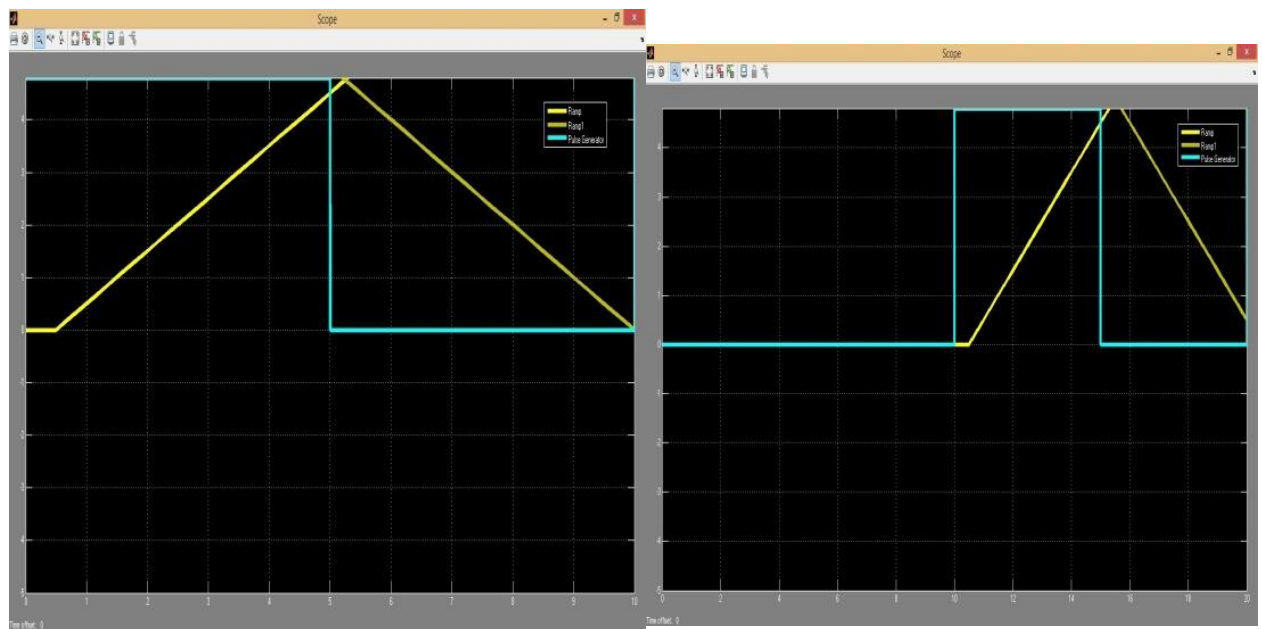

Fig. 10. Response of Cylinder 2

Fig. 11. Response of Cylinder 3 


\subsection{Discussion based on the results}

There are three scopes provided in the fig.5, on which response are obtained. Graphical responses of valves are given in fig. 9, 10 and 11 respectively.

- The graph is between response of the solenoid valve (relay) and time

- $\mathrm{Y}$ axis shows the response of the valve in the form of amplitude (voltage) and $\mathrm{X}$ axis shows the time in milliseconds (scale is 100 on $\mathrm{X}$ axis)

- The response of the valve can be calibrated with the position of the cylinder.

- Blue line is an Input pulse to the system and the yellow line is the response of the cylinder 1,2 and 3 respectively

- Cylinders gets forward (upward yellow line) when the input pulse (blue line) is high, whereas cylinder gets retracted when input pulse is low.

- Duration of the first cycle is 2 seconds.

- Input signal is a square wave generated from Arduino and given to the relay.

- Cylinder 1 or relay 1 responds properly to the input signal

- Cylinder 2 or relay 2 lags 50 msecs to relay 1

- Cylinder 3 or relay3 responds after completion the cycle of cylinder 1 and 2.

- $\quad$ The actual responses are almost as same as the desired PSD shown in fig 3.

\section{Conclusions}

At the end of the paper, it can be concluded that, the Pneumatic system can easily be controller using MATLAB simulink and Arduino controller. Students can easily control and manipulate the system with having any trouble in programming. There is no need to waste money behind PLC as this can be operated using a very cheap controller (Arduino).

As far as the future scope is concerned, Hydraulic Servo valve, encoder, Motors, Sensors, PID controllers also can be interfaced using this methodology. The system can also have an internet access called IOT (Internet of things) to control the entire system using internet or a webpage called online monitoring system.

\section{References}

[1]. P. Parikh, R. Vasani, and S. Sheth, "Velocity Analysis of a DC Brushed Encoder Motor using ZieglerNichols Algorithm: A Case of an Automated Guided Vehicle," Indian Journal of Science and Technology 9.38 (2016).

[2]. P. Parikh, S. Sheth, and T. Patel, "Positional Analysis of a DC Brushed Encoder Motor Using ZieglerNichols Algorithm," CAD/CAM, Robotics and Factories of the Future. Springer India, 2016. 637-650.

[3]. S. Maheriya, and P.Parikh, "A Review: Modelling of Brushed DC Motor and Various type of Control Methods," Journal for Research| Volume 1.12 (2016).

[4]. P. Parikh, N. Modi, and R. Prajapati, "Control of Industrial Pneumatic \& Hydraulic Systems using Serial Communication Technology \& Matlab."

[5]. P. Parikh, K. Joshi, and S. Sheth, "Color Guided Vehicle-An Intelligent Material Handling Mechatronic System," Proceedings of the 1st International and 16th National Conference on Machines and Mechanisms (iNaCoMM 2013), IIT Roorkee, India. 2013.

[6]. Parikh P., Shah H. and Sheth S," A Mechatronics design of a line tracker robot using Ziegler Nichols control technique for P, PI and PID controllers," International Mechanical Engineering Congress (IMEC- 2014), June 13-15, 2014. DOI: 10.13140/RG.2.1.4107.4722

[7]. P. Parikh, H. Shah and S. Sheth., "Development of a multi-channel wireless data acquisition System for swarm robots - A Mechatronic Approach using Arduino UNO and MATLAB," International Journal of Engineering Development and Research (IJEDR), ISSN:2321-9939,2 (1), pp. 717-725.

[8]. K. Tamboli, S. Sheth, V. Shah, V. Modi, V. Gandhi, and N. Amin, "Design and Development of a Mechatronic System for the Measurement of Railway Tracks," Proceeding of the International conference CCEED under IEEE, pp. 264-269.

[9]. T. Patel, S.Sheth, and P. Patel," Design of Semiautomatic Hydraulic Blanking Machine Using PLC," National Conference on Innovative \& Emerging Technologies (NCIET- 2015), pp. 410-412. DOI: 10.13140/RG.2.1.4529.6803 